\title{
РОЗРОБКА ЕЛЕКТРОНОГО ДАЙДЖЕСТУ НАУКОВИХ ДОРОБКІВ
}

\author{
Волкова А. Ю. ${ }^{1}$, Харахаш О. В. ${ }^{2}$, Сакалюк О. Ю. ${ }^{3}$, Козуб О. О. \\ 1,2,3,4 Одеська національна академія харчових технологій, Одеса, Україна \\ ORCID: ${ }^{1}$ http://orcid.org/0000-0002-4414-6592, ${ }^{2}$ http://orcid.org/0000-0002-7405-4517, ${ }^{3}$ http://orcid.org/0000-0002-5051- \\ 518X, ${ }^{4}$ http://orcid.org/0000-0002-0481-9203 \\ E-mail: ${ }^{1}$ volkovanastasia.w@gmail.com, ${ }^{2}$ sash.harahash@gmail.com, 3 sakaliuk.olexiy@ gmail.com, \\ 4 oksana.olegovna.kozub@gmail.com
}

Copyright (C) 2018 by author and the journal "Automation of technological and business - processes. This work is licensed under the Creative Commons Attribution International License (CC BY). http://creativecommons.org/licanses/by/4.0

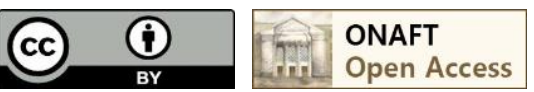

\section{DOI: https://doi.org/10.15673/atbp.v12i1.1698}

Анотація. Метою проекту було створення програмного забезпечення, а саме веб-платформи, який надає можливість впорядкувати, нормалізувати та спростити пошук наукового доробку, щуо міститься серед періодичних наукових видань. Для досягнення поставленої мети, в розробиі програмного продукту, було сформовано наступні задачі: проаналізувати основні проблеми предметної області; проаналізувати існуючі аналогів; обрати засоби реалізачії програмного продукту; розробити програмний продукт.

Об'єктом дослідження виступив онлайн-сервіс, щуо впорядковує та спрощує пошук серед наукових публікащій. На даний момент, існує декілька аналогів, але головною відмінністю поміж ними є те, щзо дані програмні продукти не містять перелік наукових видань Одеської національної академії харчових технологій.

Для розробки серверної частини електронного дайджесту був обраний фреймоврк Spring та мова програмування

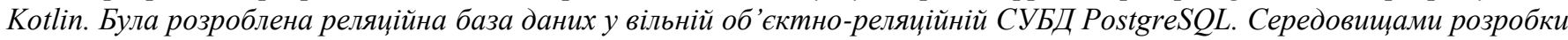
були обрані IntelliJ IDEA ma DataGrip. Для розробки клієнтської частини електронного дайджесту було використано середовище розробки PHPStorm з інтелектуальним редактором, який підтримує передові технології розробки та включає в себе підтримку баз даних, також володіє повним набором інструментів для розробки Інтернет ресурсу. Інтерфейс дайджесту було побудовано за допомогою HTML5/CSS3, для побудови інтерактивного та функиіонального додатку було використано мову JavaScript, а також фреймворк Воотstrap для поліпшення розробки.

Abstract. The aim of the project was to create software, namely a web-based platform, which provides an opportunity to streamline, normalize and simplify the search for scientific content contained in periodicals. In order to achieve this goal, in the development of the software product, the following tasks were formed: to analyze the main problems of the subject area; analyze existing analogues; to choose the means of realization of the software product; to develop a software product.

The object of the study was an online service that streamlines and simplifies the search for scientific publications. At the moment, there are several analogues, but the main difference between them is that these software products do not contain a list of scientific publications of the Odessa National Academy of Food Technologies.

The Spring Framework and the Kotlin programming language were chosen to develop the server side of the electronic digest. A relational database was developed in the free PostgreSQL object-relational database. The development environments were chosen by IntelliJ IDEA and DataGrip. PHPStorm's development environment with a smart editor, which supports advanced development technologies and includes database support, also has a complete set of tools for developing an online resource, was used to develop the electronic digest client part. Digest interface was built using HTML5 / CSS3, JavaScript and Bootstrap framework were used to build the interactive and functional application.

Ключові слова: Web 2.0, Science 2.0 веб-ресурс, база даних, PostgreSQL, HTML5, CSS3, програмне забезпечення, наукові доробки, пошук інформації, науково-технічна бібліотека, розробка програмного продукту, діджіталізація

Keywords: Web 2.0, Science 2.0 web resource, database, PostgreSQL, HTML5, CSS3, software, scientific research, information search, scientific and technical library, software development, digitization

\section{1. Теоретична складова}

Інформаційні технології та автоматизація робочого процесу відіграють важливу роль у організації процесів моніторингу, аналізу та популяризації наукових здобутків, зокрема це відбувається за допомогою електронних 
http://www.atbp.onaft.edu.ua/

ресурсів. Для швидкого доступу та пошуку наукових доробків технології Web 2.0 надають такі переваги, як можливість глобального пошуку у Інтернет мережі, вільний дистанційний доступ до наукових праць, індивідуальні ресурси/платформи наукових видань та повідомлення про оновлення дослідницьких тем.

Кількість наукового контенту, який щорічно потрапляє до мережи налічує сотні тисяч одиниць, серед яких, принаймні декілька тисяча належить науковцям Одеської національної акадмії харчових технологій. 3 метою систематизації наукового контенту вчених ОНАХТ було прийнято рішення створити електронний дайджест.

В якості електронного дайджесту наукових публікацій/контенту буде виступати електронний ресурс, який надаватиме вільний доступ до інформації про наукові доробки. Основними етапами розробки електронного ресурсу є визначення структурних цілей, розробка інструментарію, вибір наукових видань, та розробка зручного та функціонального інтерфейсу [2, 3].

Таким чином, застосування Web 2.0 в рамках Science 2.0 є основою для зручної організації монтіторингу наукових доробків, та інформації про них.

\section{2. Результати проведенного дослідження}

Програмне забезпечення (ПЗ) розроблене в рамках дослідження становить інформаційно-управляючу систему для публікацій науковців ОНАХТ. Розроблене ПЗ має трьохрівневу архітектуру, що складається з клієнта, сервера додатку та серверу бази даних. Клієнтська частина Інтернет ресурсу реалізує інтерфейс, відправляє запити до серверної частини та оброблює відповідь отриману зі сторони серверу. Серверна частина отримує запити від клієнта, виконує обчислення та відправляє сформовану сторінку по мережі. Для безпечного та правильного формування і роботи 3 данними, була створеня реляційна база даних.

В якості системи управління базою даних (СУБД) було обрано PostgreSQL, об'єктно-реляційна база даних. Це означає, що, хоча в першу чергу це реляційна модель, вона також включає в себе такі функції, як успадкування таблиць і перевантаження функцій, які частіше пов'язані з об'єктно-орієнтованими БД. Postgres здатний ефективно обробляти декілька завдань одночасно, ця властивість відома як паралелізм. Це досягається без блокувань читання завдяки реалізації MVCC, что забезпечує атомарність, узгодженість, ізоляцію і довговічність своїх транзакцій, також відомих як відповідність ACID [1, 4]

В якості середовища розробки інтегроване, інструментальне середовище, призначене для допомоги розробникам у створенні програмних додатків за наявністю всього необхідного інструментарію. Багато IDE включають додаткові можливості для тестування, організації та рефакторінга коду. Додаткові функції, такі як автозаповнення, поряд 3 можливостями збірки, значно розширюють можливості розробника і підвищують швидкість їх розробки. Вибір оптимальної IDE залежить від таких факторів, як мовна підтримка, потреби операційної системи і витрат, пов'язаних 3 використанням IDE і т.д.

IntelliJ IDEA - інтегроване середовище розробки програмного забезпечення 3 підтримкою багатьох мов програмування. Система поставляється у вигляді урізаної по функціональності безкоштовної версії «Соттипіtу Edition» і повнофункціональної комерційної версії «Ultimate Edition», для якої активні розробники відкритих проектів мають можливість отримати безкоштовну ліцензію. Програмне забезпечення JetBrains IntelliJ IDEA - це провідне середовище швидкої розробки на мові програмування Java. IntelliJ IDEA становить високотехнологічний комплекс інтегрованих інструментів програмування, включає інтелектуальний редактор записів 3 розвинутими засобами автоматизації, потужні інструменти рефакторингу коду, вбудована підтримка стандартів розробки на рівні підприємств, механізм інтеграції середовища тестування та системами керування версій, унікальний інструмент оптимізації та перевірки коду, а також інноваційний візуальний конструктор графічних інтерфейсів.

Для зв’язку бази даних (БД) з додатком використорвувалась технології RESTful API. RESTful API - це прикладний програмний інтерфейс, який використовує НТTР- запити для отримання, вилучення, розміщення і видалення даних. API-інтерфейс RESTful, також званий веб-службою RESTful, заснований на технології передачі стану уявлень (REST), а його архітектурний стиль і підхід до комунікацій, часто використовується при розробці веб-сервісів. Одним 3 ключових переваг API REST $є$ те, що він забезпечує гнучкість. Дані не прив'язані до ресурсів або методів, тому REST може обробляти кілька типів викликів, повертати різні формати даних. Така гнучкість дозволяє розробникам створювати API, який відповідає їх потребам, а також потребам різних клієнтів [2]. Цей протокол також виділяється завдяки своїй масштабованості. Завдяки розподілу між клієнтом і сервером продукт може бути масштабований командою розробників без особливих труднощів [6, 7].

Як зазначалось вищє архітектура серверу була розроблена як RESTful API, клієнтська частина має доступ до даних з БД через посилання конкретних запитів до серверу. URL цих запитів має вигляд «../арі/назва_таблиці/httр_метод/..». Дані, які відправляються до клієнтської частини мають формат JSON та кодування UTF8. Також ці дані можуть розрізнятися за змістом, якщо наприкінці запиту є постфікс «-tree» - це означає, що в даних відображатимуться певні обов'язкові зв'язки [5].

3. Програмна підтримка дослідження. Опис основних процедур та функцій

Збережена SQL функиія пошуку на рівні БД 
Функція publication_records(title, date, authors, keywords, all_record) містить 2 курсори_authors та _keywords, які конвертують прийняті данні у масив. Це дозволяє нам обирати декілька рядків із результату великого запиту. Через створений курсор можна отримувати рядки, застосовуючи команду FETCH.

$$
\text { _authors }=\text { concat }(\{', \text {, authors, ' }\} \text { ') }: \because \text { character varying []; }
$$

_keywords = concat ('\{', keywords, '\}') :: character varying[];

Параметр all_record приймаючи значення true видає усі існуючі записи у базі даних та відправляє їх на клієнт на головну "Книгу"

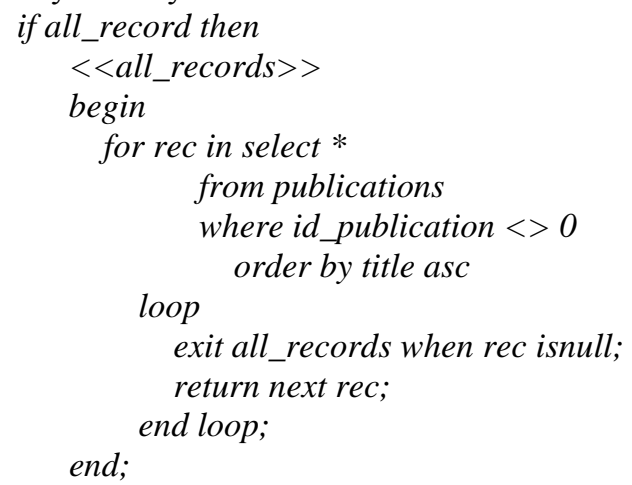

Запит у циклі вже дозволяє виконувати пошук по усім параметрам: дата, ключові слова, автори та назва. for rec in select distinct p.id_publication,
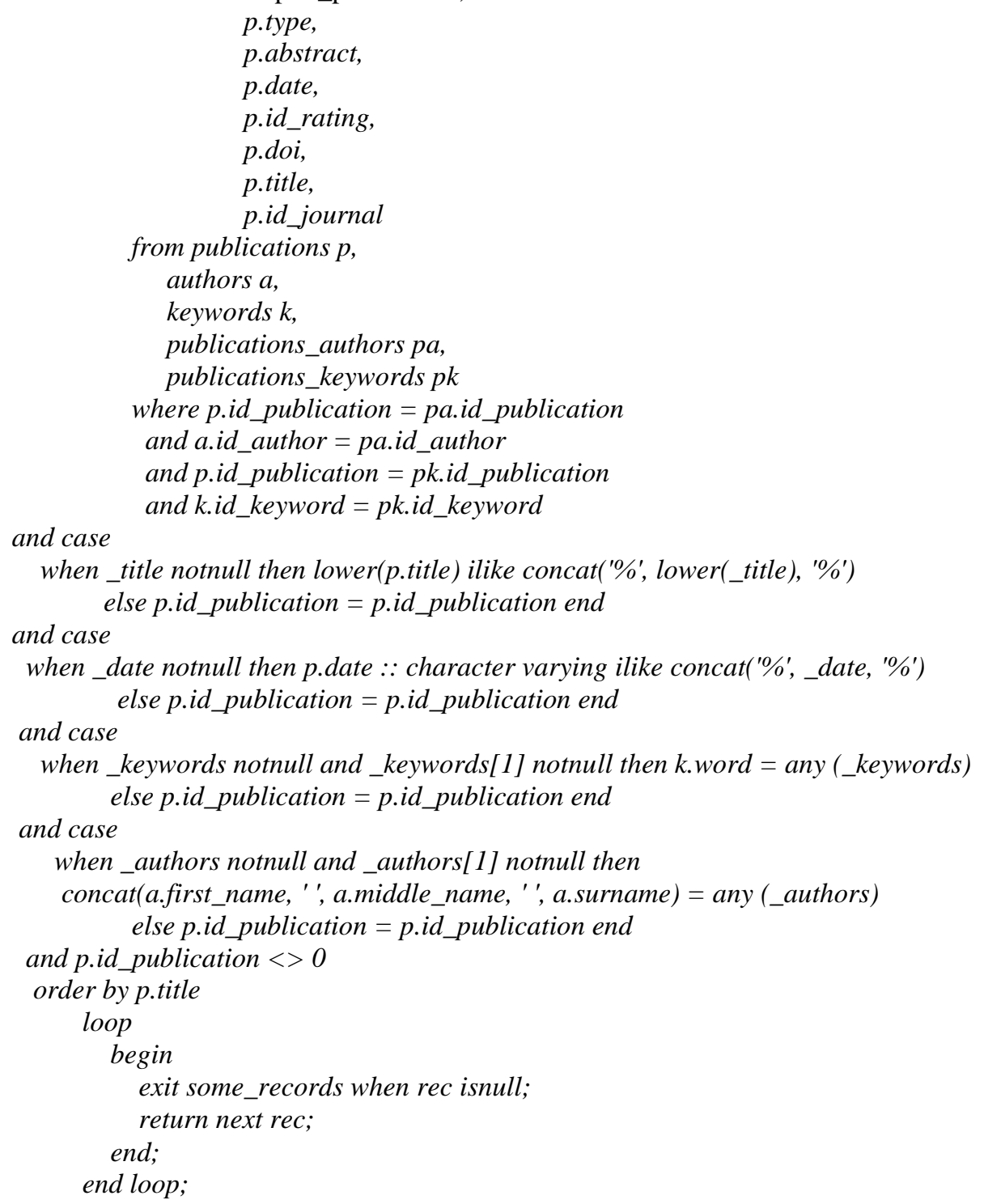
При цьому, враховано, що користувач може ввести неповну назву публікації, таким чином, пошук назви працює по принципу “містить слово”. Також враховано можливість ігнорування регістру текста, тому не буде важливим у якому форматі отримуються дані для пошуку.

when_title notnull then lower(p.title) ilike concat('\%', lower(_title), '\%')

else p.id_publication $=p$.id_publication end

Пошук по ключовим словам та авторам відбуваються по масиву даних за допомогою оператора ANY. Так як ці запити знаходяться у циклі, проходить пошук по масиву на кожному новому ключовому слові чи авторі.

and case

$$
\begin{aligned}
& \text { when_keywords notnull and_keywords[1] notnull then } k \text {.word }=\text { any (_keywords) } \\
& \text { else } p \text {.id_publication }=p . i d \_p u b l i c a t i o n \text { end } \\
& \text { and case } \\
& \text { when_authors notnull and_authors[1] notnull then } \\
& \text { concat(a.first_name, ' ', a.middle_name, ' ', a.surname) }=\text { any (_authors) } \\
& \text { else p.id_publication }=p . i d \_ \text {publication end }
\end{aligned}
$$

SQL функиія створення нових записів в БД

Для кожної таблиці в БД було створено по 4 функції для основних операцій:

- вибірка (SELECT FROM);

- видалення (DELETE FROM);

- додавання (INSERT INTO);

- оновлення (UPDATE SET).

Це було зроблено для зручності використання SQL запитів у програмному коді самого додатка.

Кожна така функція має наступний функціонал:

• вхідні параметри мають значення за замовчуванням, тому при виклику в неї можна передавати не всі параметри;

- кожна така функція повертає результат у вигляді запису з таблиці, для якої була створена;

- якщо операція невдала (такого запису не існує, друкарська помилка в переданому параметрі, неможливо додати/оновити через повторення даних тощо) повертається нульовий запис із таблиці, де в кожній комірці міститься «Нульове значення»;

- для запитів на вибірку або деяких видалень присутня можливість вказати параметр «всі записи» та, якщо є, вказати додатковий параметр конкретизації.

Нижче наведено приклад такої функції на додавання нового запису в існуючий розділ публікацій. У переліку вхідних параметрів для кожного задаються значення за замовчуванням. Якщо було передано null або нічого, береться значення default для цього стовпця:

create or replace function publication_insert_type publication_type DEFAULT NULL::publication_type,

_abstract text DEFAULT NULL::text,

_date date DEFAULT NULL::date,

_doi character varying DEFAULT NULL::character varying,

title character varying DEFAULT NULL::character varying,

_stars double precision DEFAULT NULL::double precision,

_seen integer DEFAULT NULL::integer,

_title_journal character varying DEFAULT NULL::character varying)

returns SETOF publications

language plpgsql

as

$\$ \$$

declare

rec publications\%rowtype;

__id_rating int;

begin

__id_journal int;

begin

_-id_rating $=($

select (rating_insert)

_stars,

seen

)).id_rating );

_id_rating $=($

select (journal_record(

_title_journal 
)).id_journal);

insert into publications (type, abstract, date, id_rating, doi, title, id_journal)

values (_type,_abstract,_date,__id_rating,_doi,_title, __id_journal) returning * into rec;

Якщо при створенні виникає помилка, оператор ехсерtion перехопить іiі та функція поверне інформацію про помилку

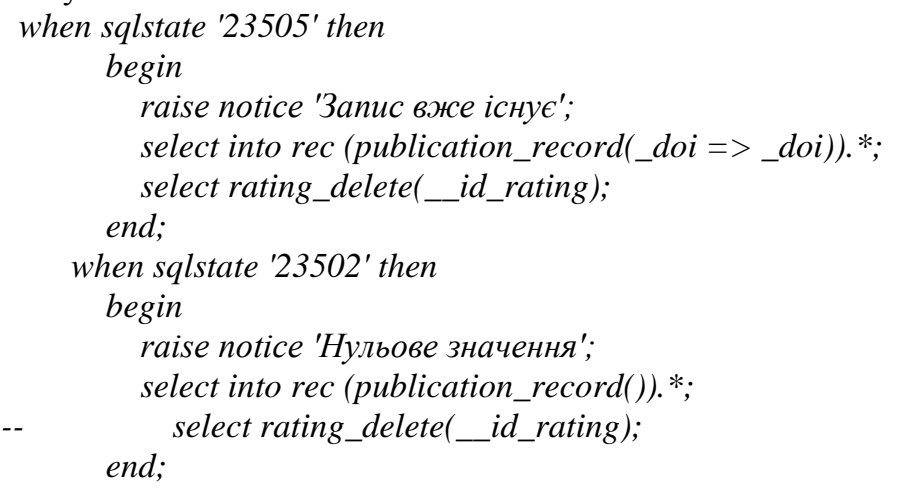

\section{3.Рекомендації щодо впровадження та використання}

Програмне забезпечення, яке розроблено в рамках дослідження, має класифікацію клієнт-серверного додатку 3 трирівневою архітектурою: клієнт, сервер додатків та сервер бази даних. Для користування даним веб-додатком необхідно мати браузер - програмне забезпечення для перегляду веб-сторінок. Рекомендується використовувати такі браузери як: Google Chrome, Safari, Mozilla FireFox, Microsoft Edge або Internet Explorer. В інших браузерах робота даного веб-додатку не перевірялась. Ресурс не передбачає мобільної версії, так як, від самого початку створювався виключно як десктопний проект.

На рисунку 1 можна побачити головну сторінку сайту, на якій можна знайти соціальні мережі організації та фіксоване меню з основними можливостями сайта.

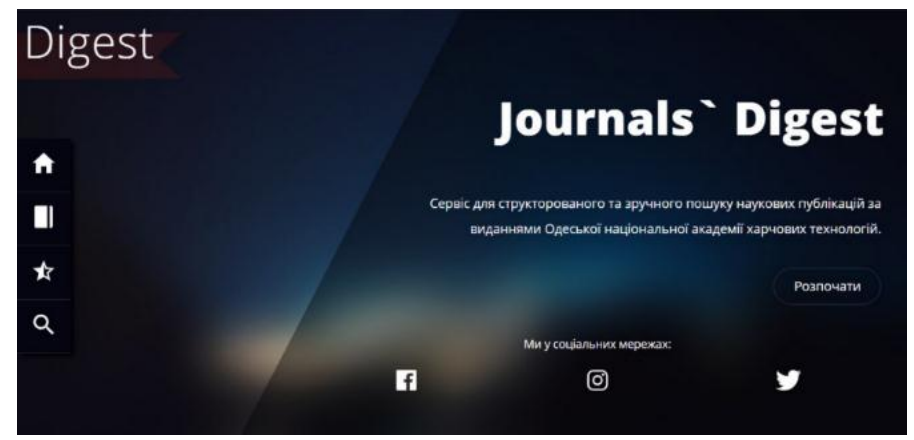

Рис. 1 - Головна сторінка сайта

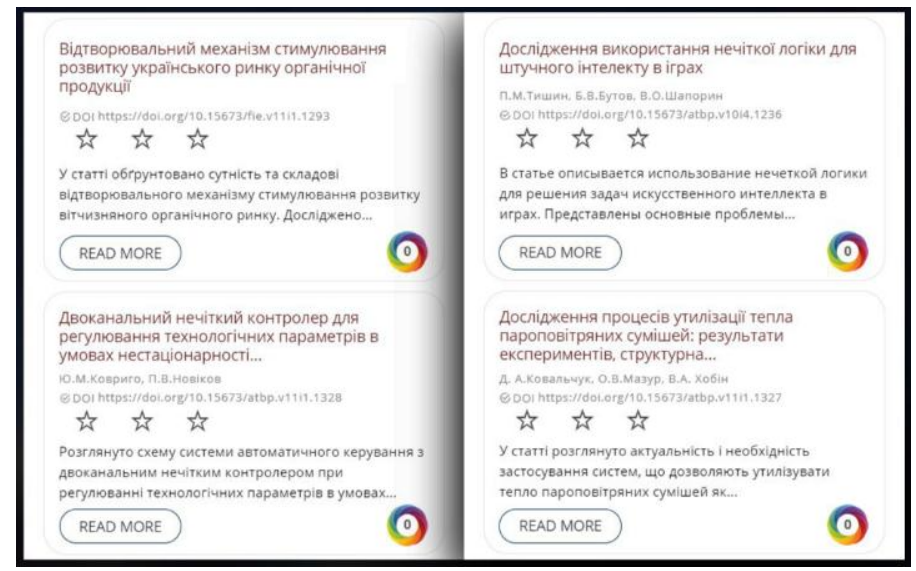

Рис. 2 - Книга сайту

Після натискання на один 3 цих елементів, користувача перенаправляє на сторінку 3 книгою публікації, як показано на рисунку 2. 
Ця сторінка містить вже знайоме користувачу фіксоване бокове меню, книгу с публікаціями, та новий елемент кнопка з розділами журналів видання ОНАХТ.

Також необхідно відзначити, що було розроблено веб-додаток який задовольняє майже всі потреби для людей які будуть його використовувати з урахуванням предметної області.

4.Практичне значення отриманих результатів

Результатом дослідження є електронний науковий дайджест, який включає в себе реалізацію всіх поставлених вимог, рішення побудованих задач та усунення виявлених проблем. Розроблений електронний науковий дайджест $є$ повноцінним, адаптивним і функціональним ПЗ, який може бути запровадженим для використання у роботі ОНАХТ для співробітників та здобувачів вищої освіти.

Список використаних джерел:

[1] Kwanya T., Stilwell C., Peter G. Library 3.0 Intelligent Libraries and Apomediation. Chandos Publishing, 2015.190 p.

[2] B. van Wyk, H. Geldenhuys. Learn 3.0 Meets Library 3.0: A Case Study / International Conference on e-Learning. 2018. $480 \mathrm{p}$.

[3] A Beginner's Guide to Neural Networks and Deep Learning // Skymind: [Веб-сайт]. URL: https://skymind.ai/wiki/neural-network (дата звернення: 07.11.2019).

[4] Object Relational Tutorial [Електронний ресурс] - Режим доступу до ресурсу: https://docs.sqlalchemy.org/en/latest/orm/tutorial.html - Назва з екрану. - Дата перегляду: 15.04.2018.

[5] The Architecture of Open Source Applications (Volume 2) SQLAlchemy [Електронний ресурс] - Режим доступу до pecypcy: http://aosabook.org/en/sqlalchemy.html - Назва з екрану. - Дата перегляду: 15.04.2018.

[6] Науменко Д. HTML, CSS, PHP, JavaScript, SQL - что и зачем? [Електронний ресурс] / Дмитрий Науменко Режим доступу до ресурсу: http://codeharmony.ru/materials/125.

[7] Язык HTML 5 - преимущества и недостатки [Електронний ресурс] - Режим доступу до ресурсу: https://seodirection.ru/html5/.

\section{References}

[1] T. Kwanya, C. Stilwell, and P. G. Underwood, Library 3.0: intelligent libraries and apomediation. Amsterdam: Chandos Publishing is an imprint of Elsevier, 2015.

[2] B. van Wyk, H. Geldenhuys, "Learn 3.0 Meets Library 3.0: A Case Study". International Conference on e-Learning, 2018.

[3] “A Beginner's Guide to Neural Networks and Deep Learning," Pathmind. [Online]. Available: https://skymind.ai/wiki/neural-network. [Accessed: 07-Nov-2019].

[4] "SQLAlchemy 1.3 Documentation," Object Relational Tutorial - SQLAlchemy 1.3 Documentation. [Online]. Available: https://docs.sqlalchemy.org/en/latest/orm/tutorial.html. [Accessed: 15-Apr-2018].

[5] "SQLAlchemy," The Architecture of Open Source Applications (Volume 2): SQLAlchemy. [Online]. Available: http://aosabook.org/en/sqlalchemy.html. [Accessed: 15-Apr-2018].

[6] "HTML, CSS, PHP, JavaScript, SQL - chto I zachem?," [Online]. Available: http://codeharmony.ru/materials/125. [Accessed: 10-Mar-2019].

[7] “SEO Direction," Jazik HTML 5 - preimushestva I nedostatki. [Online]. Available: https://seodirection.ru/html5/. [Accessed: 05-Mar-2019].

УДК 004.383.2:004.738.5:004.771

\section{ПРИНЦИПИ ПОБУДОВИ ХМАР ТЕГІВ ДАНИХ}

Хараш К. М. ${ }^{1}$, Ольшевська О. В. ${ }^{2}$, Титуренко Ж. А. ${ }^{3}$

$1,2,3$ Одеська національна академія харчових технологій, Одеса, Україна

ORCID: ${ }^{2}$ http://orcid.org/0000-0002-4512-3915, ${ }^{3}$ http://orcid.org/0000-0001-6774-1688

E-mail: ${ }^{2}$ olshevska.olga@gmail.com, ${ }^{3}$ janettrnk@gmail.com

Copyright (C) 2018 by author and the journal "Automation of technological and business - processes.

This work is licensed under the Creative Commons Attribution International License (CC BY).

http://creativecommons.org/licanses/by/4.0

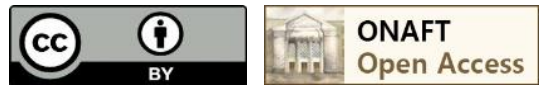

DOI: https://doi.org/10.15673/atbp.v12i1.1699 